\title{
Curcumin enhances the cytotoxic and chemo- sensitising effects of lenalidomide in human multiple myeloma cells
}

\author{
Rose Wong ${ }^{1}$, Terry Golombick ${ }^{2}$, Terrence H. Diamond ${ }^{2}$, Arumugam Manoharan ${ }^{3}$, Rajeev \\ Ramakrishna $^{3}$
}

1. Department of Medicine, St George Clinical School, University of New South Wales, Australia. 2. Department of Endocrinology, St George Hospital, Sydney, Australia. 3. Southern Sydney Haematology, University of Wollongong, NSW, Australia.

Correspondence: Terry Golombick. Address: Prichard Wing, St George Hospital, Gray Street, Kogarah, NSW, Australia 2217. Email: terry.golombick@sesiahs.health.nsw.gov.au

Received: March 11, 2013

Accepted: May 5, 2013

Online Published: May 6, 2013

DOI : 10.5430/jhm.v3n2p1

URL: http://dx.doi.org/10.5430/jhm.v3n2p1

\section{Abstract}

Background: Curcumin, the active component of the Curcuma longa plant, has been shown to potentiate the effect of the immunomodulatory drugs (IMiDs) thalidomide and Bortezomib against human myeloma cell lines and a nude mice model. Its effect on the other IMid, lenalidomide, has not been evaluated. This study aims to investigate the mechanism of action of curcumin and its potential ability to positively interact with lenalidomide.

Method: we designed an in-vitro study to investigate the cytotoxic and chemo-sensitising effects of curcumin alone and in combination with lenalidomide on the human myeloma H929 cell line.

Results: Incubation of $\mathrm{H} 929$ cells with curcumin $(30 \mu \mathrm{M})$ or lenalidomide $(2.5 \mathrm{mM})$ for 3 days resulted in $26.35 \%( \pm 1.06)$ and $30.81 \%( \pm 2.98)$ apoptotic cells respectively. When $30 \mu \mathrm{M}$ curcumin was combined with $2.5 \mathrm{mM}$ lenalidomide, $50.4 \%$ $( \pm 3.37)$ apoptotic cells were detected by flow cytometry and the increase was significant compared to either curcumin alone or lenalidomide alone (anova $p=0.0026$ ). Furthermore, gene analysis studies show that curcumin enhances the cytotoxic effect of lenalidomide via suppression of the cereblon and multi-drug resistant genes.

Conclusion: Curcumin exerts a cytotoxic effect additive to that of lenalidomide on H929 myeloma cells, and it also enhances the chemo-sensitizing effects of this agent.

\section{Key words}

Lenalidomide, Curcumin, Multiple myeloma cells, In-vitro

\section{I ntroduction}

Current treatment options for patients with multiple myeloma include the use of a combination of cytotoxic drugs and immunomodulatory drugs (IMiDs) such as thalidomide, lenalidomide, bortezomib and pomalidomide ${ }^{[1,2]}$. IMiDs have been shown to have anti-inflammatory, anti-angiogenic, pro-apoptotic and immunomodulatory properties ${ }^{[3,4]}$. Despite 
their therapeutic potential, only $80 \%$ of patients with myeloma respond to IMiDs-based therapy ${ }^{[1]}$. Factors which determine response to IMiDs have not been clearly defined.

Curcumin, the active component of the Curcuma longa plant, displays a wide range of biological activities including anti-oxidant, anti-inflammatory and cytotoxicity to numerous cancer cell types ${ }^{[5]}$. Its anti-cancer effect has been attributed to regulation of multiple cell signalling pathways involved in cell proliferation and apoptosis ${ }^{[6]}$. In vitro and in vivo studies have shown that curcumin inhibits activation of nuclear factor-kappa B (NF-kappa B), a transcription factor closely linked to chemoresistance, in various types of haematological as well as non-haematological cancers ${ }^{[7-9]}$. Sung et al ${ }^{[10]}$ have shown that curcumin can circumvent chemoresistance in vitro and potentiate the effect of thalidomide and bortezomib against human multiple myeloma in a nude mouse model. Bai \& Zhang ${ }^{[11]}$ have shown that curcumin enhances the cytotoxic effects of bortezomib in a human multiple myeloma cell line.

Recent clinical studies have demonstrated that oral administration of curcumin, even at high doses, is well tolerated and can decrease the paraprotein load, free light chains, bone turnover and \% plasma cell infiltrate into the bone marrow in some patients with monoclonal gammopathy of undetermined significance (MGUS) and smoldering multiple myeloma $(\mathrm{SMM})^{[12-15]}$.

Given that both curcumin and IMiDs have demonstrated pro-apoptotic and chemo-sensitising properties, we designed an in-vitro study to investigate the cytotoxic and chemo-sensitising effects of curcumin alone and in combination with lenalidomide on the human myeloma cell line H929.

\section{Materials and methods}

\subsection{Cell culture}

The human myeloma cell line H929 was obtained from the ATCC and maintained in RPMI 1640 medium supplemented with $10 \%$ fetal bovine serum (FBS), penicillin $(100 \mathrm{U} / \mathrm{ml})$ and streptomycin $(100 \mathrm{ug} / \mathrm{ml})$ at $37^{\circ} \mathrm{C}$ in an atmosphere of $5 \%$ $\mathrm{CO}_{2}$.

Curcumin (C3 complex from Sabinsa Corporation, Piscataway, NJ, containing 3 curcuminoids ie curcumin, desmethoxycurcumin and bisdesmethoxycurcumin) was dissolved in DMSO at $1 \mathrm{mM}$ as a stock solution and stored at $-20^{\circ} \mathrm{C}$. Lenalidomide was dissolved in DMSO (Dimethylsulfoxide) at $200 \mathrm{mM}$ as a stock solution and stored at $-20^{\circ} \mathrm{C}$. For in vitro use, dilutions of the stock solutions were made in culture medium, and filter sterilised. The maximum concentration of DMSO in the culture medium (1\%) had no effect on cell death of H929 cells.

\subsection{Evaluation of apoptosis}

Cells treated with curcumin and/or lenalidomide were cultured for 3 days before they were analysed for apoptosis using the Annexin V-FITC kit (Miltenyi Biotech). One million cells were washed and resuspended in binding buffer and stained with $10 \mu \mathrm{l}$ of Annexin V-FITC for 15 minutes at room temperature in the dark. The cells were washed once with $1 \mathrm{ml}$ of binding buffer and resuspended in $500 \mu \mathrm{l}$ of binding buffer. Five microliter of propidium iodide (PI) solution (provided) was added immediately prior to analysis by flow cytometry.

\subsection{Sample preparation and real-time PCR}

All cells used for real-time PCR analysis were cultured under the same conditions as those for evaluation of apoptosis, however the culture period was 2 instead of 3 days. Total RNA was extracted from the cells using the RNeasy mini kit (Qiagen, Melbourne, Australia), followed by complimentary DNA (cDNA) synthesis using the Superscript III first strand synthesis kit (Invitrogen, Melbourne, Australia). Real time PCR was performed on the lenalidomide target gene cereblon 
using 5'-CTCCTGCCTGCAGAGAGTGAGG-3' and 5'-TGCTCATCGTGCAAAGTCCTGC- 3' primers (NCBI Nucleotide reference NM_016302.3 ); the multi-drug resistant gene (MDR) using 5'-AAGCAGAGGCCGCTGTTCGT3' and 5'-ATCCATCCCGACCTCGCGCT-3' (NCBI Nucleotide reference NM_000927.4); and the multi-drug resistant protein (MRP) using 5'-TGGGCATCACCATGCTGCTT -3' and 5'-ACAGGTCCACCTGGGCATCC-3' (NCBI Nucleotide reference NM_004996.3 ). All real time PCR was run on a Rotor Gene RG-3000 instrument (Corbett, Qiagen, Australia), using the KAPA SYBR fast real-time PCR kit (Geneworks, Adelaide, Australia). Data were analysed using the comparative cycle threshold (CT) method normalised to the endogenous reference gene 18S (Qiagen, Melbourne, Australia), and relative to a calibrator (normalised ct value obtained from untreated cells), which was expressed as $2^{\text {-DDct }}$. The fold change in the expression of the mRNA due to treatment was calculated as $-1 / 2^{- \text {DDct }}{ }^{[16]}$.

\section{Results}

\subsection{Apoptotic effects of curcumin and lenalidomide alone and in combination on $\mathrm{H} 929$ cells}

The effect of curcumin and lenalidomide (LEN), either alone or in combination, on apoptosis of H929 cells was measured as the $\%$ of annexin V positive cells by flow cytometry after a 3-day incubation period. Incubation of H929 cells with curcumin or LEN resulted in a dose-dependent increase in cell death. Curcumin demonstrated a cytotoxic effect against H929 cells with an IC50 at $40 \mu \mathrm{M}$ (see Figure 1A) and was used at $30 \mu \mathrm{M}$ for subsequent experiments. The apoptotic effect of LEN reached a plateau at $3 \mathrm{mM}$ resulting in approximately $70 \%$ cell death after 3 days (see Figure 1B). LEN was used at $2.5 \mathrm{mM}$ for subsequent experiments.

\section{Figure 1 A}

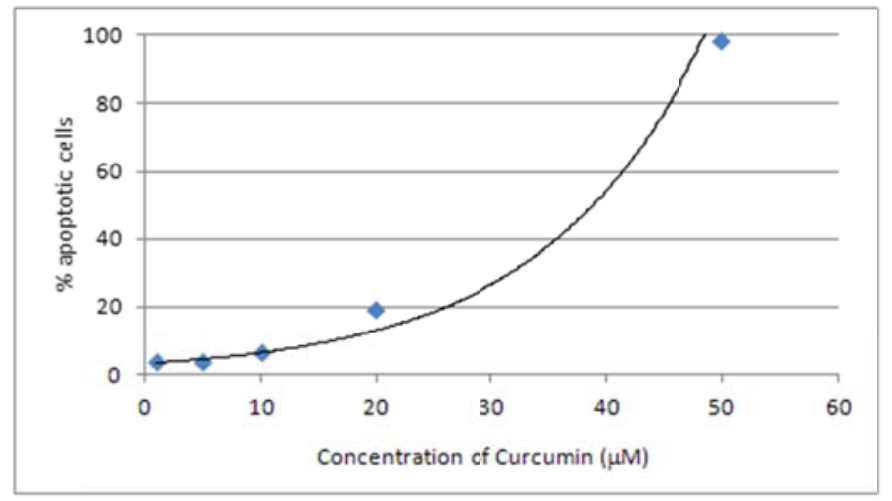

Figure 1 B

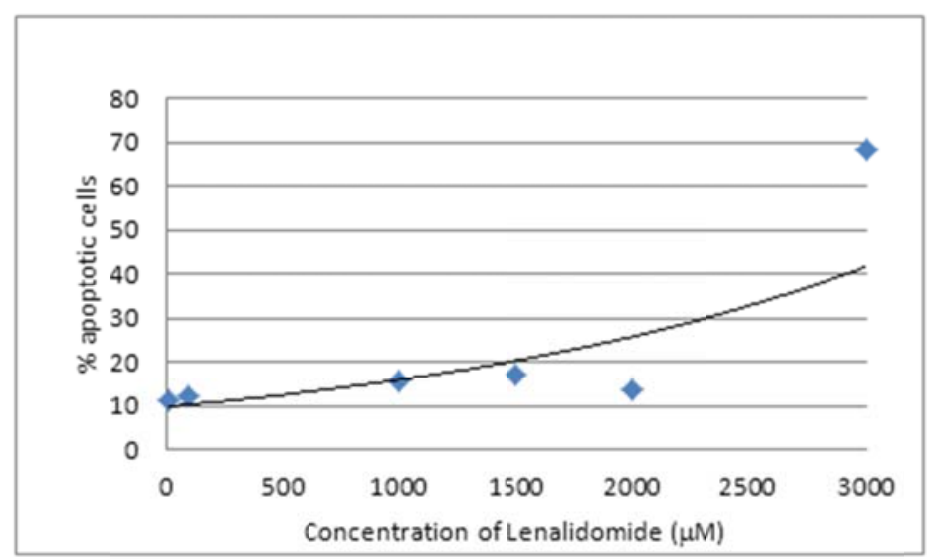

Figure 1. Apoptotic H929 cells (\%) after 3 days incubation at various concentrations of curcumin (A) and LEN (B). Each experiment was performed in duplicate. 
Incubation of $\mathrm{H} 929$ cells with curcumin $(30 \mu \mathrm{M})$ or LEN $(2.5 \mathrm{mM})$ for 3 days resulted in $26.35 \%( \pm 1.06)$ and $30.81 \%( \pm 2.98)$ apoptotic cells respectively. When $30 \mu \mathrm{M}$ curcumin was combined with $2.5 \mathrm{mM}$ LEN, $50.4 \%( \pm 3.37)$ apoptotic cells were detected by flow cytometry (see Figure 2), and the increase was significant compared to either curcumin alone or lenalidomide alone (anova $p=0.0026$ ).

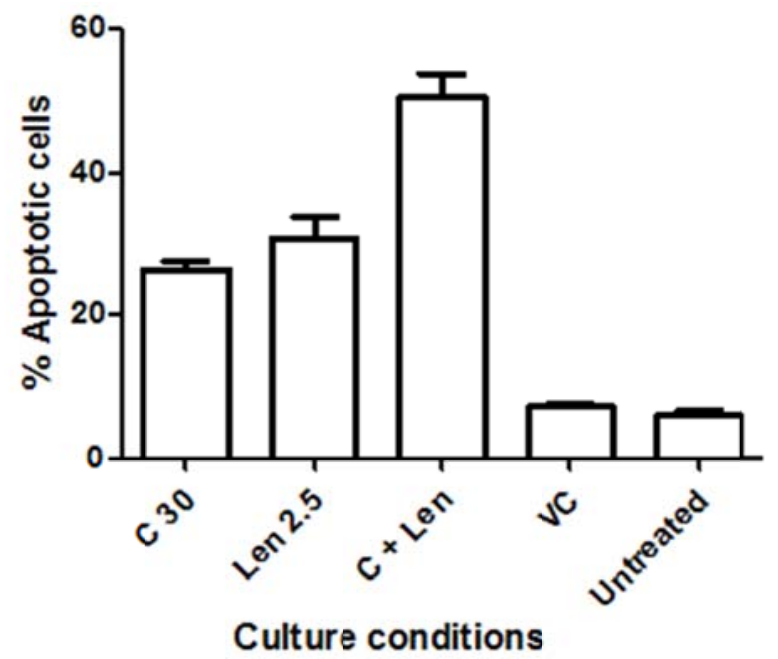

Figure 2. The percentage of apoptotic cells measured as annexin $\mathrm{V}$ positive by flow cytometry is shown for each culture condition: curcumin at $30 \mu \mathrm{M}(\mathrm{C} 30)$, lenalidomide at $2.5 \mathrm{mM}$ (Len 2.5) and combination of both curcumin and lenalidomide $(\mathrm{C}+$ Len). Minimal cell death was observed with vehicle control containing 1\% DMSO. Error bar represents SEM of duplicate experiments. The difference in vehicle control (VC) and untreated cells was not significant $(p=0.16)$.

\subsection{Effect of curcumin and lenalidomide on cereblon gene expression}

Lenalidomide suppresses expression of the cereblon gene (CRBN) resulting in a cytotoxic effect on myeloma cells ${ }^{[17] .}$ Change in the level of mRNA expression of CRBN was tested in the curcumin-treated H929 cells by RT-PCR, with LEN-treated cells acting as a positive control. A similar decrease (4.71 fold) in CRBN mRNA expression was observed in curcumin-treated and LEN-treated H929 cells. A combination of curcumin and LEN resulted in an increased suppression (7.7 fold) of CRBN mRNA expression (see Figure 3).

Figure 3. A combination of curcumin (C) and lenalidomide (LEN) reduced the expression of cereblon and MRP compared to single agents alone. Curcumin alone had a stronger effect in reducing the expression of MDR than lenalidomide alone or a combination of both $(\mathrm{C}+\mathrm{LEN})$. Error bars are from 3 separate experiments each performed in duplicate.

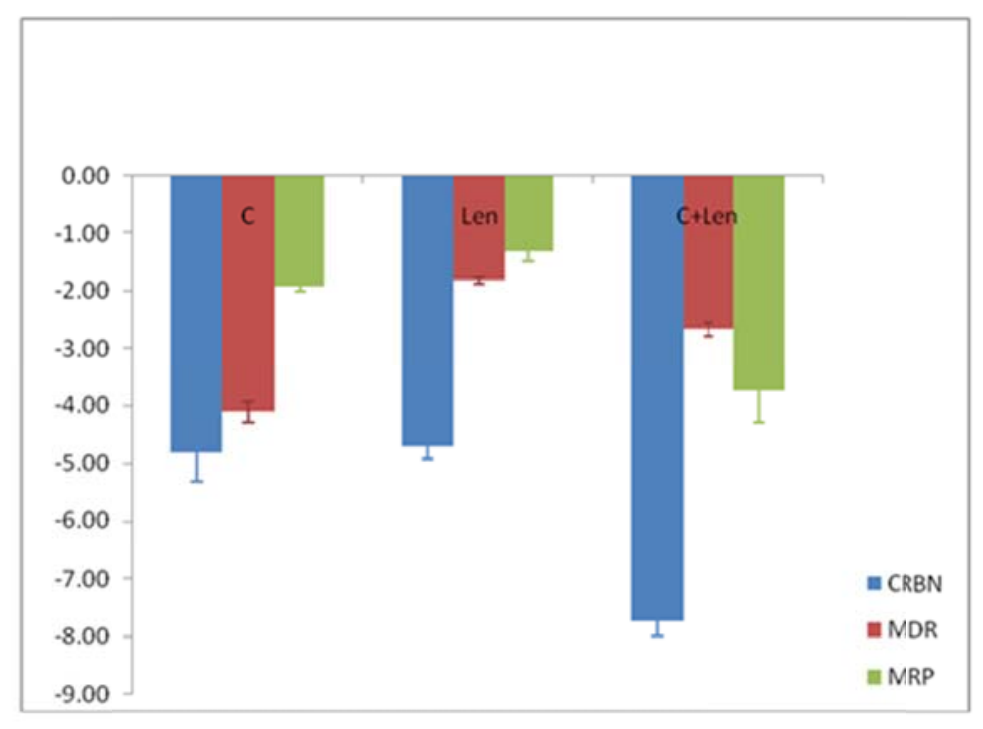




\subsection{Effect of curcumin and lenalidomide on multi-drug resistant genes}

The expression of genes associated with multidrug resistance (MDR) in multiple myeloma, MDR1 (p-gp) and the MDR protein (MRP), were analysed by real time RT-PCR. Treatment of H929 cells with either $30 \mu \mathrm{M}$ of curcumin or $2.5 \mathrm{mM}$ of lenalidomide for 48 hours decreased the expression of MDR compared to untreated cells. There was a 4-fold reduction of MDR mRNA expression as a result of curcumin treatment, while in the lenalidomide-treated cells there was a 2-fold reduction of MDR mRNA expression compared to the untreated controls. A combination of the two agents resulted in a 3 -fold reduction in the mRNA expression of the MDR gene (see Figure 3).

MRP mRNA expression decreased by 2 and 1.5-fold respectively after incubating the cells with either curcumin or lenalidomide as compared to untreated controls. Enhanced reduction of MRP mRNA expression was observed when cells were treated with a combination of both agents. An approximate 4-fold reduction in the MRP mRNA level was evident compared to the untreated controls (see Figure 3).

\section{Discussion}

This study demonstrates that both curcumin and lenalidomide exert a cytotoxic effect on H929 myeloma cells resulting in apoptosis. Furthermore, the combination of curcumin and lenalidomide enhances apoptosis of these cells. These findings are similar to those of previous studies with myeloma cell lines (U266 and H929) using curcumin and a less potent immunomodulatory drug, i.e. thalidomide ${ }^{[10]}$ and bortezomib ${ }^{[11]}$ respectively. The H929 cell line was chosen for this study because it harbours the $\mathrm{t}(4 ; 14)$ translocation, whereas the $\mathrm{U} 266$ cell line carries a $\mathrm{t}(11 ; 14)$ translocation ${ }^{[18]}$. Patients that carry the $t(11 ; 14)$ translocation are considered "low risk", while those harbouring the $t(4 ; 14)$ translocation are associated with a poor prognosis that is only partially improved by the use of lenalidomide ${ }^{[19]}$. The lack of response in patients with $t(4 ; 14)$ probably explains our in vitro observation that the H929 cells were only partially responsive to lenalidomide which reached a plateau at $3 \mathrm{mM}$.

Recent studies have demonstrated that the cereblon (CRBN) gene is a primary target for IMiD drugs like thalidomide and lenalidomide ${ }^{[17]}$. Exposure of myeloma cells to lenalidomide results in cell death, and this cytotoxic effect is accompanied by suppression of the CRBN gene ${ }^{[17]}$. Since a combination of curcumin and lenalidomide resulted in an increased apoptotic effect in this study, we sought to analyse if this cytotoxicity might be related to a change in the gene expression of CRBN mRNA. Our results confirm that mRNA expression of CRBN is similarly reduced in the presence of either curcumin or lenalidomide as compared to untreated controls and the reduction is almost doubled when the two agents were used in combination. These findings indicate that curcumin can enhance the cytotoxic effect of lenalidomide via suppression of the cereblon gene.

Multidrug resistance is a significant factor that contributes to the success or failure of chemotherapy in various types of cancer including multiple myeloma. Myeloma patients often show resistance to a number of cytotoxic drugs once they develop resistance to doxorubicin-based chemotherapy ${ }^{[20]}$. Here, we also examined the effect of curcumin and lenalidomide as single agents and in combination on the expression of two common multidrug resistant genes, the MDR1, encoding the P-glycoprotein, and the MRP gene which encodes the multidrug resistant protein. As single agents, both curcumin and lenalidomide reduced the expression of both MDR1 and MRP. A combination of both agents resulted in enhanced reduction of MRP expression. This observation has not been previously reported.

Exposure of H929 cells to curcumin alone resulted in a greater reduction in MDR1 compared to lenalidomide alone or a combination of both agents. Chen et al ${ }^{[21]}$ report that lenalidomide is not a P-gp inhibitor in vitro or in vivo. This may explain the greater MDR1 response to curcumin than lenalidomide inH929 cells. Curcumin has also been shown to reduce MDR1 gene expression in primary cells isolated from newly diagnosed and relapsed leukaemia patients ${ }^{[22]}$. 
About one third of patients with relapsed or refractory myeloma respond to thalidomide-containing treatment, and this response rate improves to $60 \%$ with a lenalidomide-containing regimen ${ }^{[23]}$. Lenalidomide-containing therapy also has the added advantage of overcoming resistance to both conventional chemotherapy and to thalidomide ${ }^{[24,25]}$. A recent review by Quach et al ${ }^{[4]}$ refers to the future optimization of lenalidomide's use in combination with other therapeutic agents. Curcumin-induced inhibition of NF-kB, which results in decreased transcription of various cytokines, could potentially augment lenalidomide's ability to disrupt bone marrow stromal support for multiple myeloma cells. Our findings and those of Sung et al ${ }^{[10]}$ suggest that curcumin can potentiate not only the cytotoxic effect of lenalidomide or thalidomide, but also enhance the chemo-sensitising effects of these agents. The clinical implications arising from these observations are two pronged: i) curcumin studies can be designed to assess the additive effects of curcumin to the current treatment protocols such as MPR (melphalan-prednisolone-lenalidomide ${ }^{[4]}$ ) and Len-Dex (lenalidomide-dexamethasone ${ }^{[4]}$ ) and ii) curcumin may be used as an alternative to corticosteroids in such protocols.

\section{Conflict of interest statement}

No conflict of interest to declare.

\section{References}

[1] Rajkumar SV, Jacobus S, Callander NS, et al. Lenalidomide plus high-dose dexamethasone versus lenalidomide plus low-dose dexamethasone as initial therapy for newly diagnosed multiple myeloma: an open-label randomised controlled trial. Lancet Oncol. 2010; 11:29-37. http://dx.doi.org/10.1016/S1470-2045(09)70284-0

[2] Palumbo A and Anderson K. Multiple Myeloma. N Engl J Med. 2011; 364 (11):1046-1060. PMid:21410373 http://dx.doi.org/10.1056/NEJMra1011442

[3] Vallet S, Palumbo A, Raje N, et al. Thalidomide and Lenalidomide: Mechanism-based potential drug combinations. Leuk Lymphoma 2008; 49:1238-1245. PMid:18452080 http://dx.doi.org/10.1080/10428190802005191

[4] Quach H, Kalff A, Spencer A. Lenalidomide in multiple myeloma: Current status and future potential. Am J Hematol. 2012; 87:1089-1095. PMid:22641420 http://dx.doi.org/10.1002/ajh.23234

[5] Shishodia S. 2012 Molecular mechanisms of curcumin action: Gene expression. Biofactors (Epub ahead of print). PMid:22996381

[6] Ravindran J, Prasad S, and Aggarwal BB. Curcumin and cancer Cells: How many ways can curry kill tumor cells selectively? AAPS Journal 2009; 11: 495-510. PMid:19590964 http://dx.doi.org/10.1208/s12248-009-9128-x

[7] Bharti AC, Donato N, Singh S and Aggarwal BB. Curcumin (Diferuloylmethane) down-regulates the constitutive activation of nuclear factor-KB and $\mathrm{IKB} \alpha$ kinase in human multiple myeloma cells, leading to suppression of proliferation and induction of apoptosis. Blood 2003; 101:1053-1062. PMid:12393461 http://dx.doi.org/10.1182/blood-2002-05-1320

[8] Bharti AC, Takada Y and Aggarwal BB. Curcumin (Diferuloylmethane) inhibits receptor activator of NF-KB Ligand-Induced NF-KB activation in osteoclast precursors and suppresses osteoclastogenesis. J. Immunol. 2004; 172:5940-5947. PMid:15128775

[9] Vadhan-Raj S, Weber DM, Wang M, et al. Curcumin downregulates NF-KB and related genes in patients with Multiple Myeloma: Results of a Phase 1/11 study. Blood. 2007; 110:1177a

[10] Sung B, Kunnumakkara AB, Sethi G, Anand P, Guha S, Aggarwal BB. Curcumin circumvents chemoresistance in vitro and potentiates the effect of thalidomide and bortezomib against human multiple myeloma in nude mice model. Mol Cancer Ther. 2009; 8(4):959-70. PMid:19372569 http://dx.doi.org/10.1158/1535-7163.MCT-08-0905

[11] Bai Q and Zhang X. Curcumin enhances cytotoxic effects of Bortezomib in human multiple myeloma H929. Int. J. Mol. Sci. 2012; 13(4):4831-4838. PMid:22606012 http://dx.doi.org/10.3390/ijms13044831

[12] Golombick T, Diamond T, Badmaev V, et al. The potential role of curcumin in patients with monoclonal gammopathy of undetermined significance - Its effect on paraproteinemia and the urinary N-Telopeptide of type 1 collagen bone turnover marker. Clin Cancer Res. 2009; 15(18):5917-5922. PMid:19737963 http://dx.doi.org/10.1158/1078-0432.CCR-08-2217

[13] Golombick T, Diamond T, Manoharan A and Ramakrishna R. Monoclonal gammopathy of undetermined significance (MGUS), smoldering multiple myeloma (SMM) and curcumin: A randomised, double-blind placebo-controlled cross-over 4g study and an open-label 8g extension study. American J Hematology 2012; 87:455-460. PMid:22473809 http://dx.doi.org/10.1002/ajh.23159

[14] Golombick T, Diamond T, Manoharan A and Ramakrishna R. Response to Vermorken et al - curcumin and free light chains.Am J Hematol 2012; 87:E80-E81. http://dx.doi.org/10.1002/ajh.23294

[15] Golombick T, Diamond T, Manoharan A and Ramakrishna R. Long term use of curcumin in two smoldering multiple myeloma (SMM) patients. Journal of Hematological Malignancies. J Hematological Malignancies 2013; 3(1):18-23. 
[16] Thomas D Schmittgen \& Kenneth J Livak. Analyzing real-time PCR data by the comparative CT method. Nature Protocols 2008;3: 1101-1108. PMid:18546601 http://dx.doi.org/10.1038/nprot.2008.73

[17] Zhu YX, Braggio E, Shi CX, et al. Cereblon expression is required for the antimyeloma activity of lenalidomide and pomalidomide. Blood 2011; 118:4771-4779. PMid:21860026 http://dx.doi.org/10.1182/blood-2011-05-356063

[18] Lombardi L, Poretti G, Mattioli M, et al. Molecular characterization of human multiple myeloma cell lines by integrative genomics: insights into the biology of the disease. Genes Chromosomes Cancer 2007; 46(3):226-38. PMid:17171682 http://dx.doi.org/10.1002/gcc.20404

[19] Kalff A, Spencer A. The t $(4 ; 14)$ translocation and FGFR3 overexpression in multiple myeloma: prognostic implications and current clinical strategies. Blood Cancer J.2012; 2:e89. PMid:22961061 http://dx.doi.org/10.1038/bcj.2012.37

[20] Schwarzenbach H. Expression of MDR1/P-glycoprotein, the multidrug resistance protein MRP, and the lung-resistance protein LPR in multiple myeloma. Med Oncology 2002; 19:87-104. http://dx.doi.org/10.1385/MO:19:2:87

[21] Chen N, Kasserra C, Kumar G, Palmisano M. Evidence does not support clinically significant lenalidomide-CCI-779 interaction via P-glycoprotein. J Clin Oncol. 2012; 30:340-1. PMid:22162571 http://dx.doi.org/10.1200/JCO.2011.39.4163

[22] Anuchapreeda S, Thanarattanakorn P, Sittipreechacharn S, et al. Inhibitory effect of curcumin on MDR1 gene expression in patient leukemic cells. Arch Pharm Res. 2006; 29:866-73. PMid:17121181 http://dx.doi.org/10.1007/BF02973907

[23] Dimopoulos M, Spencer A, Attal M, et al. Lenalidomide plus dexamethasone for relapsed or refractory multiple myeloma. N Engl J Med. 2007; 357:2123-2132. PMid:18032762 http://dx.doi.org/10.1056/NEJMoa070594

[24] Singhal S, Mehta J, Desikan R, et al. Antitumor activity of thalidomide in refractory multiple myeloma. N Engl J Med. 1999; 341:1565-71. PMid:10564685 http://dx.doi.org/10.1056/NEJM199911183412102

[25] García-Sanz R, González-Porras JR, Hernández JM, et al. The oral combination of thalidomide, cyclophosphamide and dexamethasone (ThaCyDex) is effective in relapsed/refractory multiple myeloma. Leukemia 2004; 18:856-63. PMid:14973508 http://dx.doi.org/10.1038/sj.leu.2403322 